\title{
Splenic irradiation in treating warm autoimmune haemolytic anaemia
}

\author{
H MARKUS, J C FORFAR
}

\begin{abstract}
An elderly man with severe congestive heart failure was noted to have a haemoglobin concentration of $87 \mathrm{~g} / 1$ and a reticulocyte count of $13 \%$. Direct Coombs test yielded a positive result and the serum contained a moderate amount of warm antibody (IgG class). Steroids were given, but to no avail, and the patient's condition precluded splenectomy. A course of splenic irradiation was therefore tried (midline dose $2000 \mathrm{cGy}$ (rads)), and 60 days later the blood film showed similar appearances to those in patients treated successfully by splenectomy. Haemoglobin concentration subsequently rose to normal.

Splenic irradiation may offer a simple treatment for resistant warm autoimmune haemolytic anaemia when splenectomy is contraindicated.
\end{abstract}

\section{Introduction}

Splenectomy is a well recognised treatment for warm autoimmune haemolytic anaemia. Splenic irradiation is used in a variety of haematological disorders but not in warm autoimmune haemolytic anaemia. We describe a patient with idiopathic warm autoimmune haemolytic anaemia who responded to splenic irradiation.

\section{Case report}

A 73 year old man with hypertension and a two year history of congestive heart failure was admitted with severe cardiac failure and massive ascites. Abdominal ultrasound showed mild splenomegaly $(14 \mathrm{~cm})$ in addition to ascites, and cardiac ultrasound showed globally very poor left ventricular function. Haemoglobin concentration was $87 \mathrm{~g} / \mathrm{l}$ with $13 \%$ reticulocytes. The direct Coombs test yielded strongly positive results with anti-IgG but negative results with anti-C3 antibodies. An eluate of the cells showed large

Cardiac Department, John Radcliffe Hospital, Headington, Oxford OX3 9DU H MARKUS, BM, senior house officer JC FORFAR, MD, clinical reader

Correspondence to: Dr Forfar. amounts of warm antibody showing no specificity; serum contained moderate amounts of free antibody. Underlying causes of warm autoimmune haemolytic anaemia were excluded: he had never taken methyldopa, he was negative for antinuclear factor, and bone marrow examination showed erythroid hyperplasia only.

He was treated with prednisolone $40 \mathrm{mg}$ daily, parenteral diuretics, and vasodilators. Anaemia persisted despite doubling of the dose of prednisolone and the addition of azathioprine $150 \mathrm{mg}$ daily, the latter being increased to $250 \mathrm{mg}$ daily later. Owing to his poor haemodynamic state and ascites he was considered unsuitable for splenectomy, and splenic irradiation was begun 50 days after admission. A midline dose of $2000 \mathrm{cGy}$ (rads) was given by anterior and posterior fields in 10 daily treatments. Sixty days later a blood film showed appearances similar to those after splenectomy, with HowellJolly bodies. The concentration of haemoglobin rose progressively after day 65 to $104 \mathrm{~g} / \mathrm{l}$ on day 81 and $137 \mathrm{~g} / \mathrm{l}$ on day 175 , despite discontinuation of the azathioprine and substantial reduction in steroids (figure).

Result of the direct Coombs test remained persistently strongly positive

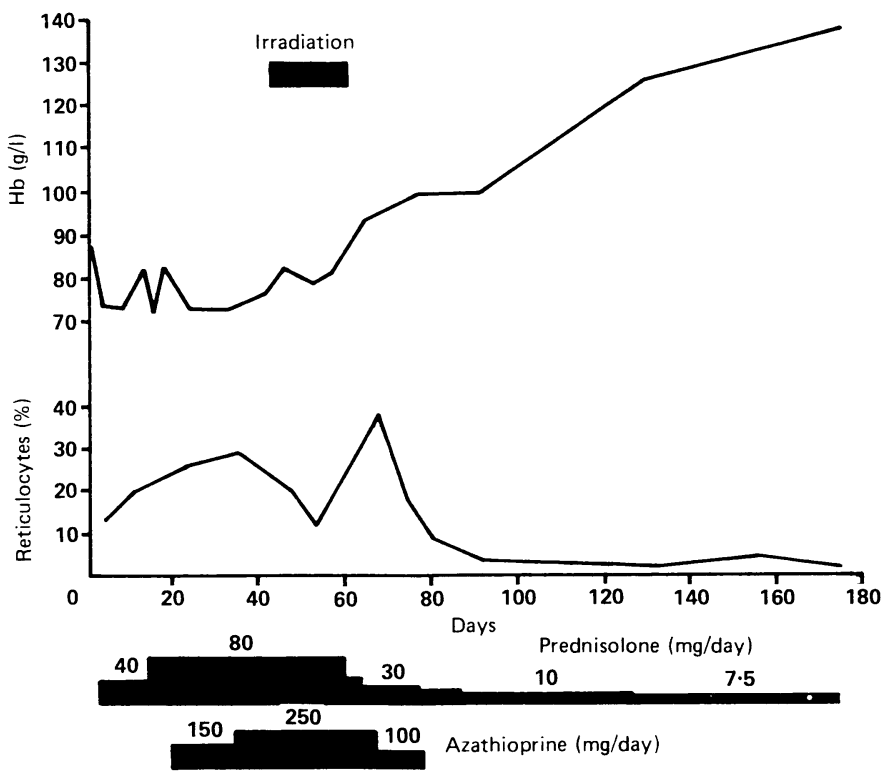

Haemoglobin $(\mathrm{Hb})$, reticulocyte count, and drug treatment before, during, and after splenic irradiation. 
and both serum and eluate showed large amounts of antibody. The patient remained well at follow up, and a weight loss of $20 \mathrm{~kg}$ was maintained with moderate oral doses of diuretics.

\section{Discussion}

Warm autoimmune haemolytic anaemia is conventionally treated with steroids, to which about $90 \%$ of patients respond. ${ }^{1}$ In nonresponders immunosuppression and splenectomy have been used. Splenectomy is effective in about half the cases, ${ }^{2}$ so splenic irradiation might be expected to produce a benefit. This, however, was not confirmed in two reports of its use from the 1950s. ${ }^{3}{ }^{4}$ Both of these cases were unusual in showing a persistently negative response on direct Coombs test. Furthermore, splenectomy is most effective with IgG non-complement fixing autoantibodies, ${ }^{5}$ which our patient possessed, and we might expect splenic irradiation to be similar. Such data were not available in the previous two cases.

Our patient failed to respond to steroids or azathioprine, but after an uncomplicated course of splenic irradiation the haemoglobin concentration returned to normal despite the continued presence of circulating antibody and a positive response to the direct Coombsw test. A delayed response to azathioprine cannot be excluded but the time course and maintained rise without azathioprine make thiso explanation less likely. Splenic irradiation may thus offer a simplee treatment in patients with resistant warm autoimmune haemolytic anaemia in whom splenectomy is contraindicated.

We thank Drs Laing, Holt, Bolton, and Key for their help and Professor PT Sleight for permission to report the case.

\section{References}

1 Worlledge S. Immune haemolytic anaemias. In: Hardistry RM, Weatherall DJ, eds. Blood and ix disorders. Oxford: Blackwell Scientific, 1982:479-514.

2 Welch CS, Dameshek W. Splenectomy in blood dyscrasias. N Engl f Med 1950;242:601-6.

3 Sokal G. Hypersplenisme hemolytique. Presence d'un anticorps aux caracteres inhabituels. Revu@u Belge de Pathologie et de Médecine Experimentale 1957;26:95-105

4 Heni F, Blessing K. Beschreibung zweier schwerer erworbener idiopathischer haemolytischer: anamien. Klin Wochenschr 1954;32:481-5.

5 Winthrobe MM. Clinical hematology. Philadelphia: Lea and Febiger, 1981:932.

(Accepted 22 Fuly 1986)

\title{
Metabolic abnormalities in children of non-insulin dependent diabetics
}

\author{
R D G LESLIE, H P VOLKMANN, M PONCHER, I HANNING, H ORSKOV, \\ K G M M ALBERTI
}

\begin{abstract}
Non-insulin dependent diabetes appears to be an inherited condition. A study of young offspring of non-insulin dependent diabetics was conducted to determine whether metabolic abnormalities could be found at a young age before clinical diabetes developed. Thirteen patients with non-insulin dependent diabetes were selected who fulfilled the following criteria: $(a)$ they had a sibling who also had non-insulin dependent diabetes, $(b)$ their spouse was non-diabetic, and $(c)$ the offspring were aged between 12 and 45 years, not diabetic, and available for study. All 32 offspring had a $75 \mathrm{~g}$ oral glucose tolerance test, and results in 13 of them, one randomly selected from each family, were compared with 13 controls of similar age, sex, and weight. The offspring had significantly higher fasting concentrations of glucose, higher proportions of haemoglobin $A_{1}$, and higher concentrations of insulin, $C$ peptide, and glucagon. After glucose challenge the increases in both glucose and $C$ peptide concentrations were significantly greater in the offspring. These differences were maintained in all 32 offspring when compared with 18 controls of
\end{abstract}

Diabetic Department, King's College Hospital, London SE5 9RS

R D G LESLIE, MD, Wellcome Trust senior fellow and consultant physician $\mathrm{H} P$ VOLKMANN, $M D$, research fellow

Department of Medicine, Royal Victoria Infirmary, Newcastle upon Tyne M PONCHER, MD, research fellow

I HANNING, BSC, research fellow

K G M M ALBERTI, MD, professor of medicine

Kommunehospitalet, Aarhus, Denmark

H ORSKOV, MD, professor of experimental medicine

Correspondence to: Dr Leslie. similar age, sex, and weight; seven of the 32 offspring had impaired glucose tolerance.

These results indicate that young offspring of selected non $\stackrel{\mathbb{\Omega}}{\Omega}$ insulin dependent diabetics can show extensive metabolic $\overrightarrow{\vec{O}}$ changes including impaired glucose tolerance. These changes 3 are associated with hyperinsulinaemia and hyperglucagonaemia.

\section{Introduction}

Non-insulin dependent diabetes appears to be inherited: identical twins are usually concordant for the disease, and patients often haveo a similarly affected relative. ${ }^{1}$ The nature of the inherited defect, 3 however, is unknown. The islet cells in non-insulin dependento diabetics are histologically normal, and, in general, they secrete an? insulin with normal biological activity. ${ }^{2}$ Glucose intolerance in theseo patients is therefore probably due to either decreased insulin secretion or decreased insulin sensitivity, or both. ${ }^{34}$ A study of nondiabetic co-twins of patients with non-insulin dependent diabetes, $\triangle$ shortly before they also developed the disease, suggested that noninsulin dependent diabetes was preceded by detectable metabolico abnormalities; these changes included an impaired insulin response to oral glucose challenge, which therefore may be an early marker for the disease. ${ }^{5}$

This study aimed at showing whether similar metabolic abnor-o malities could be found in the young, apparently normal offspringo of non-insulin dependent diabetics.

\section{Patients and methods}

We selected a consecutive series of 13 patients with established noninsulin dependent diabetes attending the diabetic clinic in Newcastle duringo 1982, who fulfilled the following criteria: $(a)$ a sibling also had non-insulin ${ }^{+}$ 